\title{
Optimization of Steel Chemistry for MnS Precipitation on Oxide Inclusions in Si/Mn Deoxidized Steel
}

\author{
Han S. KIM, Hae-Geon LEE and Woo-Gwang JUNG ${ }^{1)}$
}

\begin{abstract}
Department of Material Science and Metallurgical Engineering, Pohang University of Science and Technology, San 31 Hyoja-dong, Nam-gu, Pohang, 790-784 Korea

1) School of Metallurgical and Materials Engineering, Kookmin University, 861-1 Chongnung-dong, Songbuk-gu, Seoul, 136-702 Korea
\end{abstract}

\begin{abstract}
A technique for optimization of steel chemistry for MnS precipitation on oxide inclusions has been developed through employing the computational thermodynamic method. The optimum composition of Si/Mn deoxidized steel was estimated to be $\mathrm{Fe}-0.1$ mass $\% \mathrm{C}-0.1 \mathrm{mas} \% \mathrm{Si}-1.5$ mass $\% \mathrm{Mn}-0.01$ mass $\% \mathrm{O}-0.007$ mass $\% \mathrm{~S}$. The prediction was validated by experiments using a semi-levitation melting technique. The inclusions mainly consisted of $\mathrm{MnO}^{-\mathrm{SiO}_{2}}$ oxides with MnS precipitates. The observed morphology revealed a possibility of both oxide and sulfide having been precipitated as liquid phase, although the existing thermodynamic data do not support this to occur.
\end{abstract}

KEY WORDS: steel; deoxidation; inclusion; oxides; MnS precipitation; steel chemistry; optimization.

\section{Introduction}

Since the early 1990 s, effective utilization of fine oxides as nucleation site for austenite-to-ferrite transformation of steel has attracted much attention ${ }^{1-8)}$, and sulfides precipitated on oxide inclusions are considered to play an important role in providing nucleation site for intragranular acicular ferrite. In particular, oxides or inclusions that are formed during solidification in a few micrometers or smaller in size have been reported to be effective for the formation of intragranular acicular ferrite ${ }^{6}$. Such formation of the intragranular ferrite(IGF) phase is considered to greatly contribute to ferrite grain refinement ${ }^{6,9-12)}$.

Several mechanisms have been proposed to account for the way in which non-metallic inclusions enhance the nucleation of acicular ferrite ${ }^{13-17)}$. Manganese sulfide(MnS) precipitated on an oxide inclusion has been suggested to provide a potent nucleation site for formation of $\mathrm{IGF}^{3,13,18-19)}$. Creation of $\mathrm{Mn}$-depleted zone in the vicinity of $\mathrm{MnS}$ in the steel matrix are considered to facilitate the formation of $\mathrm{IGF}^{16,20-22)}$ since $\mathrm{Mn}$ is an austenite stabilizer.

Behavior of $\mathrm{MnS}$ precipitation on oxide inclusions is affected to a great extent by the chemistry of both the inclusions and the matrix steel. However, the chemistry of the inclusions that are formed during solidification is governed primarily by the steel chemistry. Therefore, it is vitally important to elucidate in a quantitative manner the interrelationship among the steel chemistry, the inclusions chemistry and the precipitation behavior of $\mathrm{MnS}$ on the inclusions.

In the present study, it has been attempted to develop a technique using thermodynamic computational technique to optimize the steel chemistry to result in precipitation of secondary inclusions during solidification on which $\mathrm{MnS}$ islands readily precipitate out during a prolonged heating process afterwards such as reheating for hot rolling. $\mathrm{Si} / \mathrm{Mn}$ deoxidized structural steel has been employed for sample computation for the optimization and the theoretically derived results were tested and proved to be valid through experiments.

\section{Optimization of steel chemistry}

In the present study, the optimum steel chemistry is defined as the steel chemistry that results in formation of inclusions on which $\mathrm{MnS}$ can readily precipitate out. $\mathrm{Si} / \mathrm{Mn}$ deoxidized structural steel has been chosen for the optimization, and hence the carbon and manganese contents were predetermined to be 0.1 and 1.5 mass $\%$, respectively. Since the number density of inclusions is important for ferrite grain refinement ${ }^{10,23-24)}$, somewhat higher total oxygen content of $100 \mathrm{ppm}$ was chosen. Then optimum silicon and sulfur contents were estimated using thermodynamic equilibrium computation. An extensive computer software called ChemSage ${ }^{25)}$, which has been developed for use with PC, together with solution databases provided by GTT-Technologies ${ }^{26}$ ) was employed for thermodynamic prediction. In summary, the steel chemistry to start with for optimization is $\mathrm{Fe}-0.1$ mass $\% \mathrm{C}-\mathrm{X}$ mass $\%$ $\mathrm{Si}-1.5$ mass $\% \mathrm{Mn}-0.01$ mass\% $\mathrm{O}-\mathrm{Y}$ mass $\% \mathrm{~S}$. The task on hand is now to find $\mathrm{X}$ and $\mathrm{Y}$.

\subsection{Optimization of silicon content}

Inclusions or precipitates that form in $\mathrm{Si} / \mathrm{Mn}$ deoxidized steel are mainly manganese silicates. Therefore, variation of the sulfur solubility of the Mn-Si-O-S system was first evaluated using thermodynamic computational technique and the results are given in Figure 1. These results are favorably compared with the experimental data reported by Hasegawa et $\mathrm{al}^{27)}$. It is seen that, for all the temperatures examined, the sulfur solubility sharply increases with increasing the relative content of $\mathrm{MnO}$ in the system. However, there is a $\mathrm{MnO}$ fraction for a given temperature above which increase in the sulfur solubility with $\mathrm{MnO}$ 
fraction becomes insignificant. It is also seen that there is a range of $\mathrm{MnO}$ fraction in which the sulfur solubility drastically decreases with decreasing temperature. In other words, there is a range of $\mathrm{MnO}$ fraction in which $\mathrm{MnS}$ can readily precipitate out on cooling.

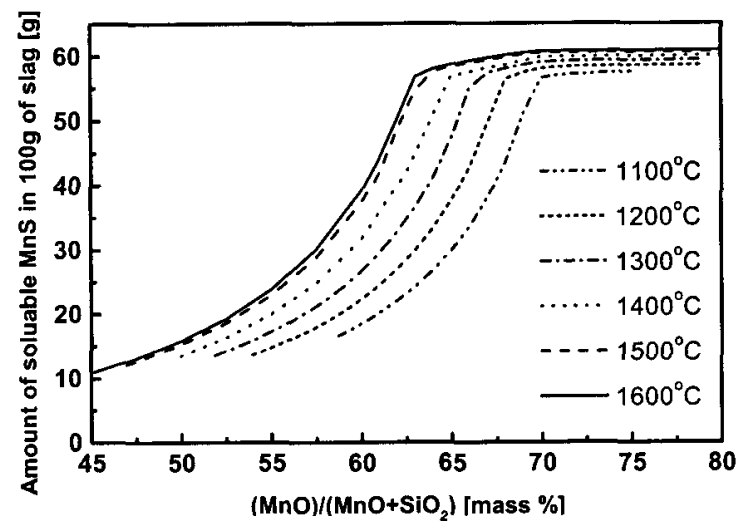

Fig.1 Solubility of sulfur in Si-Mn-O-S system

Since the relative content of $\mathrm{MnO}$ and level of sulfur in inclusions formed in $\mathrm{Si} / \mathrm{Mn}$ deoxidized steel are determined by silicon and sulfur content of the steel, respectively, it should be possible to find a steel chemistry which results in formation of inclusions whose compositions are the optimum for MnS precipitation on them. Figure 2 is the computed results of compositions of inclusions that form in a number of different steel chemistry and different temperatures. In the computation the sulfur content was fixed at $70 \mathrm{ppm}$, the reason for this choice will be given shortly. It is seen that the $\mathrm{MnO}$ fraction in the manganese silicate inclusions is dependent to a large extent on the silicon content in the steel; the higher the $\mathrm{Si}$ content in the steel, the lower the $\mathrm{MnO}$ fraction in the inclusions. At $1,600^{\circ} \mathrm{C}$ the sulfur content in the inclusions is low regardless of silicon content in the steel. As the temperature decreases below $1,500^{\circ} \mathrm{C}$, however, the sulfur content sharply increases until $\mathrm{MnS}$ precipitates out. This increase is due to solidification of steel and preferential distribution of sulfur in the liquid phase. Further decrease in temperature results in a gradual change of inclusions composition, and the sulfur content varies, but stays at the saturation limit for the given composition of the inclusions.

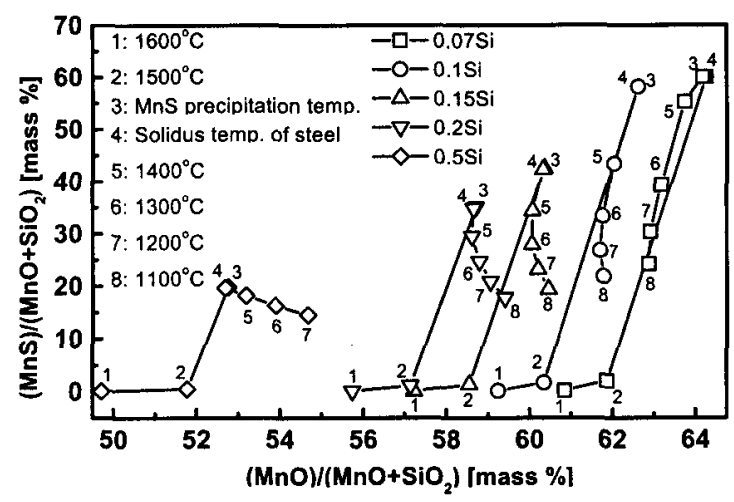

Fig.2 Prediction of change in sulfur solubility in $\mathrm{MnO}-\mathrm{SiO}_{2}$ inclusion
An important fact to be seen in Fig.2 is that the extent of the decrease in sulfur content after the initial precipitation of $\mathrm{MnS}$, i.e., from point 4 to point 5 , is different for different Si content in the steel. The larger the extent of decrease, the greater susceptibility of $\mathrm{MnS}$ precipitation. With this in mind, it can easily be seen from the figure that the results with 0.1 mass $\% \mathrm{Si}$ show the optimum condition for $\mathrm{MnS}$ precipitation on the inclusions.

\subsection{Optimization for sulfur content}

Obviously, Sulfur is required for MnS precipitation, but existence of excessive amount of sulfur should be avoided because of its harmful effect on the physical properties of steel.

The effect of sulfur content on the initiation temperature of $\mathrm{MnS}$ precipitation is thermodynamically evaluated and the results are given in Figure 3. In the calculation, $\mathrm{Mn}$ was kept at 1.5 mass\%. With increasing the sulfur content, the initiation temperature of $\mathrm{MnS}$ precipitation increases until the sulfur content reaches about $70 \mathrm{ppm}$. At this level of sulfur content, the first precipitation of $\mathrm{MnS}$ occurs at the solidus of the steel, $1,480^{\circ} \mathrm{C}$. Since the majority of the secondary inclusions form near or below the solidus, $\mathrm{MnS}$ precipitation will most likely occur on the secondary inclusions of manganese silicates. at a temperature above the solidus, however, some MnS precipitations would occur independent of the secondary inclusions, because the secondary inclusions would hardly form at the temperature. Therefore, the optimum sulfur content should be around $70 \mathrm{ppm}$ for $1.5 \mathrm{mass} \% \mathrm{Mn}$.

\subsection{Thermodynamic behavior of the optimized steel on}

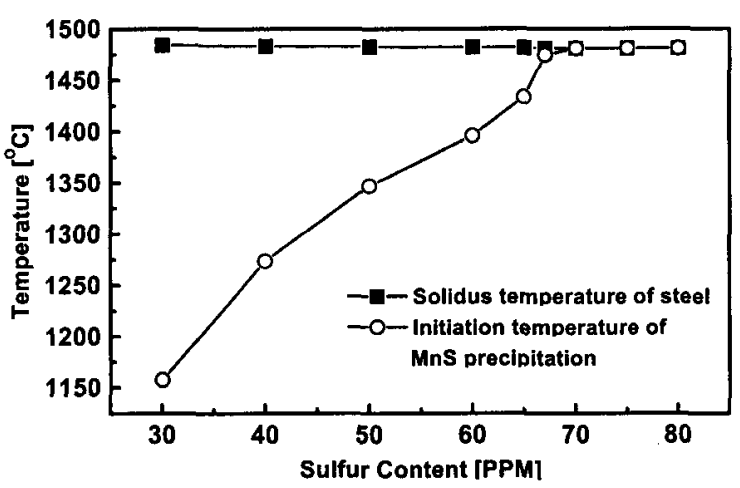

Fig.3 Effect of sulfur content on the initiation temperature of MnS precipitation

cooling

Table 1 shows the optimized composition of steel that can best result in MnS precipitation on manganese silicate secondary inclusions. The thermodynamic behavior of this steel on cooling from $1,600^{\circ} \mathrm{C}$ to $1,100^{\circ} \mathrm{C}$ was computed and the results are given in Figure 4. It is clearly seen that the sulfur content in the inclusions increases sharply as the temperature approaches the solidus and eventually reaches the saturation limit. Further cooling results in decrease in the sulfur content in the inclusions, meaning $\mathrm{MnS}$ precipitating out from the inclusions. Mass balance analysis 
enables it possible to predict the amount of $\mathrm{MnS}$ precipitated not on the inclusions, but independently in the steel matrix. Fig. 4 shows that the amount of the independent $\mathrm{MnS}$ should not be appreciable, in comparison with $\mathrm{MnS}$ precipitated on the inclusions.

Table 1 The optimum steel chemistry for MnS precipitation on $\mathrm{MnO}-\mathrm{SiO}$,(estiamted).

\begin{tabular}{ccccc}
\hline $\mathrm{C}$ & $\mathrm{Si}$ & $\mathrm{Mn}$ & $\mathrm{S}$ & $\mathrm{O}$ \\
\hline 0.1 & 0.1 & 1.5 & 0.07 & 0.001 \\
\hline
\end{tabular}

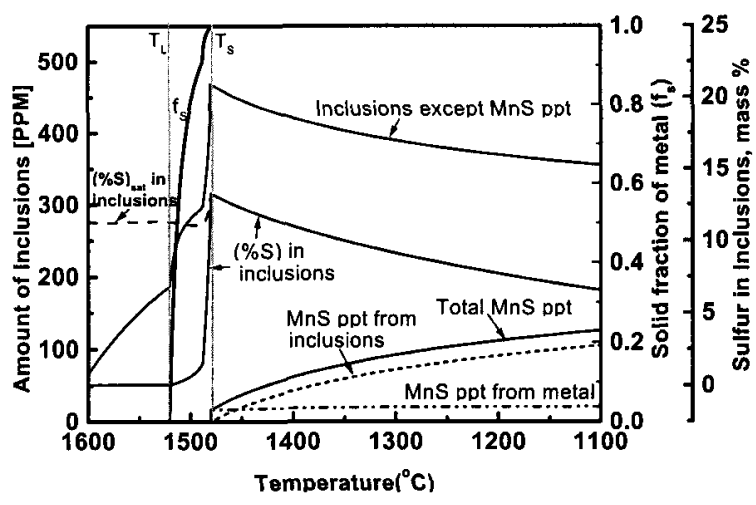

Fig.4 Precipitation behavior of MnS during cooling for the optimized steel chemistry(estimated).

From Fig. 4 it may be possible to draw the following summary:

1) There exist some primary inclusions formed at temperatures above the liquidus, but the majority of the inclusions are secondary ones since they form during solidification.

2) The sulfur content in the inclusions is far from saturation until the temperature has been lowered close to the solidus, at which the inclusions become saturated with sulfur.

3) Further decrease in temperature results in $\mathrm{MnS}$ precipitation mostly on the existing inclusions. The amount of independent $\mathrm{MnS}$ is not appreciable.

In general, primary inclusions are large in size, and harmful to the physico-chemical properties of steels in most cases. The secondary inclusions which form during solidification are small in size (a few micrometers or smaller in diameter), and are beneficial, for instance, for grain refinement.

\section{Experimental}

In order to confirm the validity of the optimization technique above-mentioned, experimental work was

undertaken by employing the semi-levitation technique which enables the removal of primary inclusions to be possible with ease.

\subsection{Master Alloy Preparation}

About $300 \mathrm{~g}$ of electrolytic iron with $0.33 \mathrm{~g}$ of $\mathrm{Fe}_{2} \mathrm{O}_{3}$ powder and $0.05 \mathrm{~g}$ of $\mathrm{FeS}$ powder was melted by induction heating in a magnesia crucible of $40 \mathrm{~mm}$ in diameter and of $100 \mathrm{~mm}$ in depth under Ar gas atmosphere. After stabilizing the melt at $1600^{\circ} \mathrm{C}$, ferro-carbon of $6 \mathrm{wt} . \% \mathrm{C}$ was added aiming at $0.1 \% \mathrm{C}$ in the steel melt. Then pure metal of $\mathrm{Mn}$ and $\mathrm{Si}$ were added subsequently.

The melt was held for 30 s after deoxidation and then about $100 \mathrm{~g}$ of melt was sucked into fused silica tubes $(5 \mathrm{~mm}$ ID) to make samples in a rod shape. The composition of the rod specimen is given in Table 2 .

\subsection{Semi-levitation Experiment}

Samples for semi-levitation experiment were prepared by cutting the rod specimen. The weight of each sample was adjusted to $0.75 \mathrm{~g}$. The schematic diagram of experimental apparatus employed in the semi-levitation experiment is shown in Figure 5. The samples were melted on an alumina substrate using induction heating $(200 \mathrm{kHz})$ in an atmosphere of $\mathrm{He}$ and $\mathrm{CO}$ gas mixture. $\mathrm{CO}$ gas was used to prevent oxidation reaction between oxygen and carbon in the melt from taking place. By controlling the partial pressure of $\mathrm{CO}$ in the atmosphere in an adequate range, the oxygen content in the samples could be maintained to the desirable value during semi-levitation experiment.

Table 2 The composition of master alloy of rod specimen

\begin{tabular}{ccccc}
\hline $\mathrm{C}$ & $\mathrm{Si}$ & $\mathrm{Mn}$ & $\mathrm{S}$ & $\mathrm{O}$ \\
\hline 0.11 & 0.11 & 1.56 & 0.0072 & 0.0099 \\
\hline
\end{tabular}

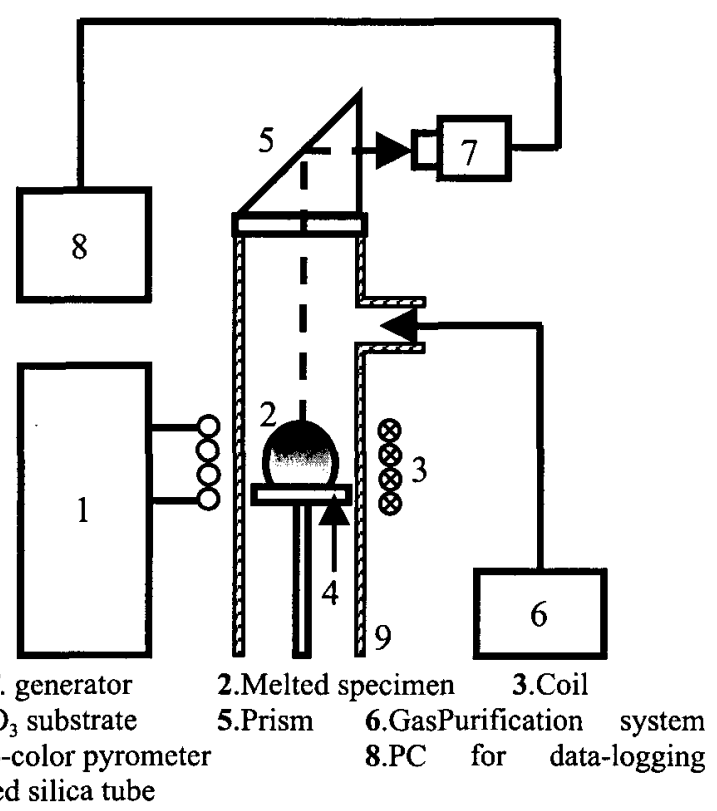

Fig.5 Schematic diagram of experimental arrangement for semi-levitation melting.

After melting, the melt was held at $1,600^{\circ} \mathrm{C}$ in the period of $1 \mathrm{~min}$, and then cooled to $850^{\circ} \mathrm{C}$ at a predetermined cooling rate using a PID controller. Three different cooling rates, i.e., $50^{\circ} \mathrm{C} / \mathrm{min}$., $200^{\circ} \mathrm{C} / \mathrm{min}$. and $500^{\circ} \mathrm{C} / \mathrm{min}$. were employed. The samples were then cut, polished and 
quantitatively analyzed on the transverse cross section using SEM. The morphology and the size of inclusions in each sample were evaluated. And the compositions of inclusions were also measured by EDS analysis.

\subsection{Experimental Results}

The typical morphology of the inclusion found in the steel is shown in Figure 6. It is readily seen that the inclusion is $\mathrm{MnO}-\mathrm{SiO}_{2}$ oxide containing small amount of sulfur, and MnS has precipitated out on it. The bright area of the inclusion corresponds to $\mathrm{MnS}$ phase while the dark area is the $\mathrm{MnO}-\mathrm{SiO}_{2}$ oxide. This is in good agreement with the prediction from the thermodynamic computation given in Fig.4. From the morphological image, it can be easily deduced that $\mathrm{MnS}$ was formed by precipitation and growth on the oxide inclusion which had acted as the heterogeneous nucleation site for $\mathrm{MnS}$ precipitation.

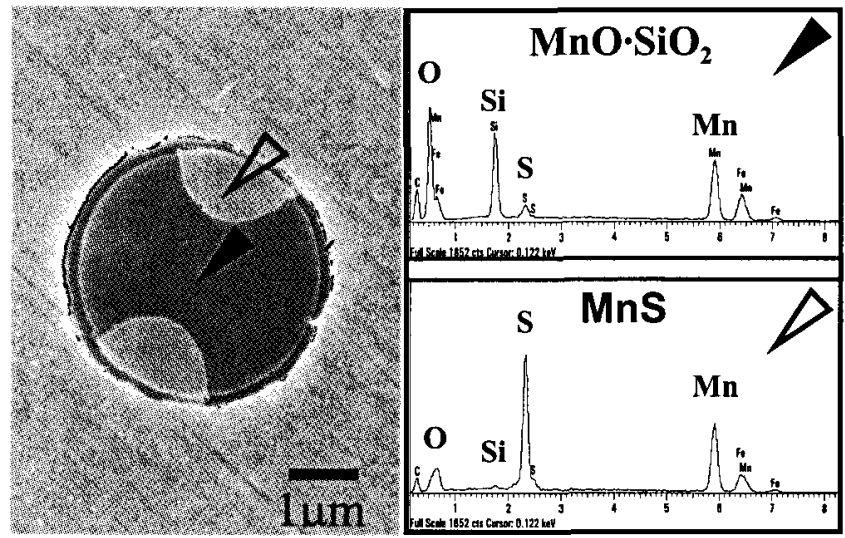

Fig.6 Typical example of $\mathrm{MnS}$ precipitation on a $\mathrm{MnO}-\mathrm{SiO}_{2}$ oxide inclusion.

MnS precipitates were formed mainly on the oxide inclusions and the number of MnS particles which exist independently in the matrix was extremely scarce even in the case of high cooling rate of $500^{\circ} \mathrm{C} / \mathrm{min}$. The above experimental results are good accord with the theoretical prediction through thermodynamic computation given earlier.

\section{Discussion}

\subsection{Probability of MnS precipitation on inclusions}

It is true that solidification process does not follow the equilibrium path, and hence there must be discrepancy to some extent between the experimental results of solidification and the thermodynamic equilibrium prediction. Although the thermodynamic analysis predicts formation of $\mathrm{MnS}$ on the secondary inclusions, there might be some inclusions which do not have $\mathrm{MnS}$ precipitates on them. In the present experimental study, it was found that there indeed exist some inclusions without $\mathrm{MnS}$ islands on them. However, its fraction is not large, and more than $90 \%$ of the secondary inclusions are with $\mathrm{MnS}$ precipitation. Wakoh et al. ${ }^{28,29)}$ have reported the influence of various kinds of oxide nuclei on the MnS precipitation. It was reported in their study that $\mathrm{Mn}$-Ti oxide provided a most effective substrate for $\mathrm{MnS}$ precipitation and thus facilitated fine dispersion of $\mathrm{MnS}$ in the steel matrix. Figure 7 compares the present results with the ones of Wakoh et al. ${ }^{28)}$ It is clearly seen that the precipitation ratio of $\mathrm{MnS}$ in present study is comparable to or even higher than that of $\mathrm{Mn}-\mathrm{Ti}$ oxide, which had been reported to have the highest precipitation ratio.

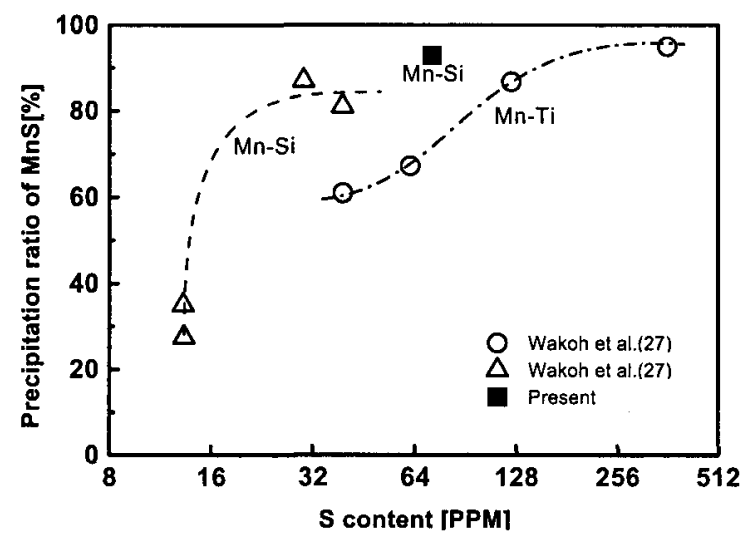

Fig.7 Change in the precipitation ratio of $\mathrm{MnS}$ with sulfur content in steel for different kinds of deoxidation elements.

4.2 Some considerations on the mechanism of $\mathrm{MnS}$

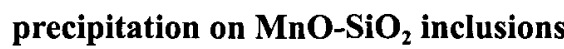

From the thermodynamic estimation as shown in Fig.4, $\mathrm{MnS}$ was expected to precipitate after sulfur saturation in $\mathrm{MnO}-\mathrm{SiO}_{2}$ inclusions. Further decrease in temperature will cause $\mathrm{MnS}$ to grow owing to the solubility of $\mathrm{Mn}$ and $\mathrm{S}$ in $\mathrm{MnO}-\mathrm{SiO}_{2}$ inclusion decreasing. From the morphological features of both oxide and sulfide shown in Fig. 6, however, it is strongly suspected that $\mathrm{MnS}$ as well as $\mathrm{MnO}-\mathrm{SiO}_{2}$ were liquid phases when they formed. $\mathrm{MnS}$ islands in fact contain $\mathrm{Si}$ and $\mathrm{O}$ as well, although the amounts are small. Oikawa et al. ${ }^{30)}$ suggested in their study on the formation of $\mathrm{MnS}$ that nucleation and growth of $\mathrm{MnS}$ as liquid phase may occur via monotectic transformation. However, thermodynamic data available do not support existence of such miscibility gap in the $\mathrm{MnO}-\mathrm{SiO}_{2}-\mathrm{MnS}$ system at $1,200^{\circ} \mathrm{C}$. This warrants further thermodynamic and kinetic study on clarification of mechanism of $\mathrm{MnS}$ precipitation on manganese silicate inclusions.

\section{Conclusion}

A technique for optimization of steel composition for precipitating $\mathrm{MnS}$ on $\mathrm{MnO}-\mathrm{SiO}_{2}$ has been developed using computational thermodynamic method. The technique was applied to the $\mathrm{Si} / \mathrm{Mn}$ deoxidized structural steel, and the optimum chemistry was found to be $\mathrm{Fe}-0.1$ mass $\% \mathrm{C}$ 0.1 mass $\% \mathrm{Si}-1.5$ mass $\% \mathrm{Mn}-0.01$ mass $\% \mathrm{O}-0.007$ mass $\% \mathrm{~S}$. The prediction was validated by experimental results. It was observed that more than $90 \%$ of secondary inclusions were with $\mathrm{MnS}$ precipitates. This ratio was comparable or even higher than that with $\mathrm{Mn}$ - Ti deoxidized steels reported in the literature. 
The morphology of inclusions observed in the present study revealed a possibility of both oxide and sulfide inclusions having been precipitated as liquid phase. Since the existing thermodynamic data do not support this to occur, further study on the mechanism of $\mathrm{MnS}$ precipitation on the $\mathrm{MnO}-\mathrm{SiO}_{2}$ inclusion is warranted.

\section{Acknowledgements}

Financial supports by Korea Science and Engineering Foundation(under contract 981-0805-028-2) and POSCO (Pohang Iron and Steel Company) are gratefully acknowledged.

\section{REFERENCES}

1) K. Oikawa, K. Ishida and T. Nishizawa: ISIJ Int'l, 37(1997), No.4, .332.

2) M. Wakoh, T. Sawai and S. Mizoguchi: Tetsu-to-Hagané, 78(1992), No.11, 73.

3) M. Wakoh, T. Sawai and S. Mizoguchi: Tetsu-to-Hagané, 82(1996), No.7, 43.

4) T. Sawai, M. Wakoh and S. Misoguchi: Tetsu-to-Hagané, 82(1996), No.7, 37.

5) H. Goto, K. Miyazawa and H. Honma: ISIJ Int'l, 36(1996), No.5, 537.

6) J. Takamura and S. Mizoguchi: Proc. $6^{\text {th }}$ Int. Iron and Steel Cong, 1(1990), ISIJ, Tokyo, 591.

7) S. Mizoguchi and J. Takamura: Proc. $\sigma^{\text {th }}$ Int. Iron and Steel Cong, 1(1990), ISIJ, Tokyo, 598.

8) T. Sawai, M. Wakoh, Y. Ueshima and S. Mizoguchi: Proc. $6^{\text {th }}$ Int. Iron and Steel Cong, 1(1990), ISIJ, Tokyo, 605.

9) M. Díaz-Fuentes, I. Madariaga, J. M. Rodriguez-Ibabe and I. Gutiérrez: J. Construct. Steel Res., 46(1998), 413.

10) Z. Zhang and R. A. Farrar: Mater. Sci. Technol., 12(1996), 37.

11) M. A. Linaza, J. L. Romero, J. M. Rodriguez-Ibabe and J. J. Urcola: Scripta Mater, 32(1995), 395.

12) J. L. Romero, M. A. Linaza, J. I. San Martin, J. M.
Rodriguez-Ibabe and J. J. Urcola: Rev. Metall.(CENIM), 32(1996), 1.

13) R. A. Ricks, P. R. Howell and G. S. Barritte: J. Mater. Sci., 17(1982), 732.

14) R. A. Farrar and M. N. Watson: Metall. Construct., 11(1979), 285.

15) B. Ralph: Mater. Sci. Technol., 6(1990), 1139.

16) I. Madariaga and I. Gutiérrez: Scripta mater., 37(1997), No.8, 1185.

17) I. Madariaga, J. L. Romero and and I. Gutiérrez: Metall. Trans.A, 29A(1998), 1003.

18) H. Goto, K. Miyazawa, K. Yamaguchi, S. Ogibayashi and K. Tanaka: Tetsu-to- Hagané, 79(1993), No.9, 1082.

19) K. Oikawa, H. Ohtani, K. Ishida and T. Nishizawa: Tetsu-toHagané, 80(1994), No.8, 43.

20) I. Madariaga and I. Gutiérrez: Acta. Mater. 47(1999), No.3, 951.

21) J. M. Gregg and H. K. D. H. Bhadeshia: Acta mater, 45(1997), No.2, 739.

22) Y. Tomita, N. Saito, T. Tsuzuki, Y. Tokunaga and K.Okamoto: ISIJ Int'l, 34(1994), No.10, 829.

23) D. J. Abson and R. E. Dolby: Weld. Inst. Res. Bull., 19(1987), 202.

24) R. C. Cochrane and P. R. Kirkwood: in Trends in Steels and Consumables for Welding, The Welding Institute, Abingdon, 1978, 103.

25) G. Eriksson and K. Hack: Metall. Trans.B, 21B(1990), 1013.

26) GTT-Technologies, Kaiserstraße 100, 52134 Herzogenrath, Germany

27) A. Hasegawa, K. Morita and N. Sano: Tetsu-to-Hagané, 81(1995), No.12, 1.

28) Masamitsu Wakoh, Takashi Sawai and Shozo Mizoguchi: ISIJ int'l, 36(1996), No.8, 1014.

29) M. Wakoh, T. Sawai and S. Mizoguchi: Tetsu-to-Hagane, 78(1992), 1697.

30) K. Oikawa, H. Ohtani, K. Ishida and T. Nishizawa: ISIJ Int 'l., 35(1995), No.4, 402 